\title{
Exploration of External Quality Assurance System in Master of Library and Information Science (MLIS) Education
}

\author{
Junbo Zhu ${ }^{\mathrm{a}}$, Wenying Liu ${ }^{\mathrm{b}}$ \\ Xiamen University Library, Xiamen 361005, China. \\ a40712853@qq.com, bliuwy@xmu.edu.cn
}

\begin{abstract}
The urgent and important task of (in) China MLIS education is to enhance education quality. To address this question, we analyzed current status of the external quality assurance of MLIS and studied the external evaluation characteristic. Then, we proposed that the reformation program for MLIS education quality is to transform the function of the government, carry out classification assessment and promote legal system construction of education assessment based on the systematic, integrated and collaborative principle.
\end{abstract}

Keywords: Master of library and information science, MLIS; evaluation characteristic, external quality assurance system, policy proposal.

\section{Introduction}

The master of library and information science, a professional master degree called MLIS for short, was established in China on May 2010. According to the traditional education of library and information science aims to Academic talents training, MLIS is based on the professional standards of library and information science for career purpose, and to train application-oriented and high-level professional talents in the area of library and information science. Therefore, the qualified graduates of MLIS should with strong professional pertinence, unique knowledge and the practice orientation of obvious.

In this background, it is important to accelerate the establishment of external quality assurance system in MLIS postgraduate education, which is adapted to the recruitment of students scale expands unceasingly and meeting the market demand. Based on the current situation of MLIS postgraduate education development, the paper will discuss the main problems and development trend of the external quality assurance for MLIS education in our country, and put forward the principle and strategy for establishment of MLIS external quality assurance system.

\section{The MLIS Education Development Situation}

Since October 2010, the state council degree committee approved MLIS, and the recruit students unit and recruit students number increases year by year. In 2011, 15 colleges and universities across the country have enrolled 168 MLIS graduate; In 2012, the national recruit MLIS graduate student of colleges and universities increased to 16, enrollment increased by $117.9 \%$, In 2013 and 2014 also increased by $24.3 \%$ and $24.3 \%$ respectively [1]. In 2015, a total of 29 universities nationwide recruit MLIS degree graduate student, accumulative total enrollment of 2228 people. The development of MLIS education, plays a special role to enhance the economic and social level. But with the enlargement of enrollment scale, it is particularly important to strengthen and complete the MLIS education quality guarantee system construction. Therefore, under the background of the MLIS education scale expands unceasingly, and growing percent of MLIS entering examination, and deepening reform the cultivating mode, it is necessary to analyze how to develop the external quality assurance construction to adapt to the characteristics of MLIS, and to promote the virtuous cycle of MLIS postgraduate education quality management, enhance the ability to adapt to social demand [2]. 


\section{The Main Problems of External Quality Assurance for MLIS Education.}

The external quality assurance is a concept corresponding with the internal quality assurance. In general, the specialized degree graduate student education is the main external quality assurance unit of running or enrollments for the implementation of the object, launched by the government or the leadership, social intermediary agencies engaged in execution, in order to accelerate the implementation evaluation objects to achieve the intended target or enhance the quality of the assessment activities [3]. Although it makes rapid development in the scale of MLIS education, it is uneven of the practice and progress to forming effective quality evaluation and guarantee mechanism in recruitment units, and the external quality assurance overall monitoring function is not strong. These problems are mainly as follows:

The external main body is single and the quality promotion is not strong. At present, external quality control of China's MLIS education mainly by the school of Professional Degree Education Steering Committee implementation. Compared to foreign countries, to ensure the quality of China's external MLIS education in non-governmental organizations are weak, including professional institutions and social intermediary organizations, the media have not enough attention, the quality supervision and assessment of the effect is still limited, influence and authority still needs to be improved. In the future, it is very necessary to encourage industry departments and professional organizations to participate in quality supervision.

The ratio of external evaluation is little, and quality assurance process is incomplete. The MLIS education quality guarantee is given priority to with the internal management in running school, and associated with lower proportion of external quality assurance. It is mainly about the backward construction of laws and regulations in the MLIS education quality assurance. Although there is a clear access system, the subsequent cohesion, tracking the imperfection of supervision system, and quality assurance process management is incomplete. The current situation led to the school attaches great importance to the quantity than quality, and low risk with running school, the enthusiasm of the external quality assurance activities are not strong enough.

The evaluation system is "academic" and the quality assurance is not scientific enough. Due to the short history of MLIS graduate education in China, it is necessary to understand the MLIS graduate education and its quality judgment. Over the years, China's postgraduate education is based on academic degree, failed to fully reflect the quality of students' occupation development of MLIS (occupation adaptation ability, occupation qualification, occupation ability), lack of scientific evaluation results, leading role is not strong.

\section{The Main Method of MLIS Education External Quality Assurance}

At present, there are many successful external quality assurance techniques and methods at home and abroad, the basic features of these methods, rational treatment, scientific application of these methods is the basic premise of the construction of quality guarantee system of our country external MLIS education.

Conformity assessment. Conformity assessment is the assessment of the basic requirements of educational activities, and the conclusion can be used as the basis for the examination and approval of educational qualifications and the qualification of retention. MLIS conformity assessment indicators tend to the quality of teaching and students' development, including project design, teaching environment, enrollment management, teachers, curriculum, teaching management, teaching effect and students' ability, school characteristics, case construction, and there are some government departments and organizations outside the cooperation and communication etc.

Quality certification. The education quality certification is a public institution that determines whether the goals, plans, and results of a school, college, or discipline are determined by a legal institution or association. The purpose of the quality certification process is to provide a recognized, professional assessment of the quality of educational institutions or disciplines, and to promote the continuous improvement and upgrading of quality and [4]. The quality of the certification process by 
the certification application, visit guidance, self-assessment, on-site inspection, certification decision steps. These steps constitute a complete cycle, the certification conclusion is passed or not, and set a certain period of validity.

Professional ranking. Discipline ranking is one of the higher education rankings, usually released for the needs of the community and the educated, the education resources and the quality of students to assess the results of the assessment. The main function is to provide quality ranking information for the society the use of talents and the education, but also because of an open and transparent mechanism, can more effectively promote the operators to provide better service for education, and effectively improve the quality of education and the ability to adapt to society.

From the analysis of the above evaluation methods, we can see that the focus, function and service object of conformity assessment, quality certification and professional ranking are interrelated, and each has its own emphasis. There are at least two methods used in the quality assurance system of higher education in the world, and the external quality assurance of MLIS education is no exception.

First of all, the government is more suitable as a qualified assessment approval or extension assessment, on the basis of regulations for the award qualifications, so the school units must attend to maintain qualification; at the same time, periodically carry out conformity assessment, is to ensure the basic quality, the basic measures for the formation of professional degree quality supervision mechanism. Secondly, the quality certification is to comply with the needs of the industry, usually organized by non-governmental organizations, fully respond to the needs of the industry and the field, according to the consensus standards and mechanisms for certification. School units in accordance with the needs of voluntary participation, to help schools in accordance with the needs of the industry and the law of professional development, improve school programs, continuous improvement of quality. Finally, professional ranking is based on the needs of society, the government organization is usually non independent institutions, provide social services and education, school units according to the need of voluntary or passive participation, help school units to understand their own academic level, in a certain range of life quality, social satisfaction, dynamic adjustment of educational goals and plan, improve services, improve social adaptation and satisfaction degree.

\section{MLIS Education External Quality Assurance System Construction}

Construction principles. MLIS education external quality assurance is a jointly implemented by the government and non-governmental organizations of the complex social activities, to ensure the activity in the right direction and scientific methods, should fully reflect the systematic, overall and coordinated.

Systematic. System is the external quality assurance of MLIS education to become an organic part of the system. Different assessment methods in this system are related and coupled in different stages of intervention, in the whole process of quality management of MLIS education, to obtain authorization from the beginning of a degree, into a closed-loop quality management system, both import threshold control, also has a feedback process the monitoring and evaluation of running situation and so on, different stages of external security, executive body different, but the same goal.

Integrity. Integrity refers to the different degrees of MLIS education, different levels of external quality assurance should be taken into account. First, it is necessary to take into consideration the external quality assurance methods and systems for full-time and part-time professional degrees. The two is the different types of professional degree graduate education should be treated differently, classification and evaluation, to reflect their different characteristics and training orientation, can not be unified standards.

Synergy. Synergy refers to the MLIS education in the external security system, in accordance with the common goal of improving quality, the implementation of the assessment and quality assurance of the relevant subjects should be cooperation and mutual promotion, mutual supervision and mutual verification of the relationship. If the different subjects of the main implementation of the different 
evaluation methods, in the index system, intervention point, the evaluation objectives, evaluation results to achieve synergies between.

Construction method. Based on the above principles, we should take into account the following 3 aspects to grasp the construction of external quality assurance system:

Accelerate the transformation of government functions, and actively play the role of market mechanisms. The combination of the government supervision mechanism and market monitoring mechanism, encourage professional institutions and social organizations as the third party power, evaluation and supervision of quality and actively participate in MLIS education, the common strategic objectives, respect the NGO multi value orientation in MLIS education quality guarantee, encourage them from different angles and with different methods of evaluating MLIS the quality of education, strengthen school units and social contact.

According to different evaluation objects, the scientific classification evaluation method. Encourage different subjects to carry out different types of quality assurance work, and guide different subjects to classify the professional degree. According to the diverse needs of the society for the library and information science, the MLIS should have different emphases in different development stages. Any single evaluation method cannot meet the needs of different levels, different levels of MLIS education external quality assurance needs, the need to establish a scientific and reasonable, in line with the actual classification and evaluation criteria and evaluation system. Therefore, according to the purpose of evaluation and the characteristics of the object being evaluated, the appropriate evaluation method should be adopted.

Strengthen the construction of laws and regulations, and strictly regulate the activities of educational evaluation. At present, China's relevant education evaluation institutions, activities and results of the release and use of the responsibility and complaints are also no clear legal norms, fair assessment basically depends on evaluation institutions self-discipline, lack of effective binding effect, fair and rational assessment of the market healthy growth. Some of the assessment ranking in certain degree of education has adverse effects, but cannot implement effective supervision. Therefore, we should establish and perfect the relevant laws and regulations as soon as possible, establish education evaluation agencies qualification certification system, a clear assessment of the rights and duties of executive main body, make the evaluation in accordance with legal procedures of external quality assessment, do a variety of activities to ensure scientificity, fairness and reliability assessment.

\section{Summary}

At present, the market is to promote the standardization of education evaluation, there are three main aspects: one is the part of the government's activities, on the basis of government policy regulation; two is to belong to non-government activities should be incorporated into the legal institutions, evaluation activities through community regulation; three is to strengthen publicity, necessity and authority, standard evaluation. The market to enhance the rationality, improve the public assessment of normative and scientific recognition ability to create social education, specialized development environment health assessment agencies.

\section{References}

[1]. Duan Yufeng, Yin Guanjun, Wu Chengsheng. Survey Report on MLIS Program Development in China (2014) [J]. Documentation, Information \& Knowledge, 2015, (4): 96-105.

[2]. Ma Yongshuang, Guo Feijun. Research on the Quality Guarantee System of Master of Library and Information Studies Degree Education in China [J]. Information Science, 2016, 34(10): 117-121.

[3]. Han Yingxiong. Framework and Mechanism of External Quality Assurance Systems for Instructional Programs in Foreign Countries[J].Shanghai Journal of Educational Evaluation, 2013, (2): 32-38.

[4]. Zeng Yueliang. Courses Accreditation System of Library and Information Science Education in 
Australia and Its Enlightenment [J]. Library Tribune, 2016, (12):99-108. 